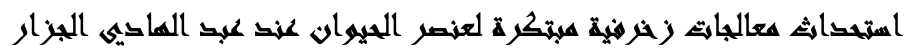

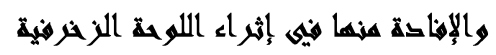

\title{
مقدمة
}

إن الطبيعة وما بها من سحر كان لها أثر وجاذبية كبيرة على روح

الفنان ونرى المعنى الأصلي للطبيعة هو كل ما خلقه الله عز وجل ويدخل في وجي ذلك الانسان نفسه وما خلقه.

ويقول (ديلاكرو اه) "ليست الطبيعة سوى قاموس ولم يحدث مطلقا ان

يعتبر احد القاموس عملا روائيا مركبا ان الفنان الحقيقي ينقب في قو اميسه عن تلك العناصر التي تتناسب مع مدركاتها و افكار ها ثم يرتبها ويغير من اشكالها ويعيد صياغتها في مهاره وحذف اما الفنان الذى يفتقد الى القدرة الابداعية فانه يقلد القاموس او يصنع منه نسخا تافهة رخيصة".

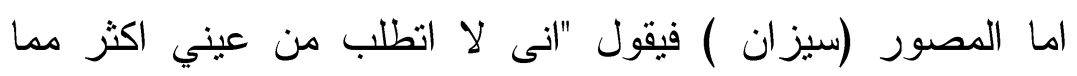
أنطلبه من اي نافذه فاني لا انظر بها الى الطبيعة ولكنني اتطلع الى الطبيعة

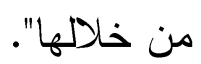

ان الطبيعة وما فيها من جاذبيه كان لها تأثير وفاعليه كبيره على

روح الفنان و المصمح و الطبيعة غنيه بالمفردات التشكيلية و النظم الجمالية . ومن ضمن مخلوقات الله في الطبيعة عنصر الحيوان استقه الفنان وتتاوله بصياغاته المختلفة على مر العصور وقد تميزت مصر بطبيعة ساحره وثراث فنى ضخم هما في حد ذاتها منبع ومعين لأثر اء رؤيه كل فنان

"ان جميع الكائنات الموجودة في الطبيعة سواء كانت حيه ام جامده تخضع لقوانين طبيعية هي ترديد للقوانين التي تحكم الكون كله بكواكبه و اجر امه لذلك بتصف كل عنصر طبيعي بما تسميه (الجمال الذاتي) وتتفاوت 


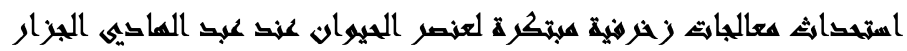

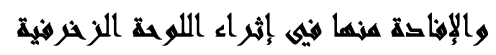

العناصر الطبيعية في صفه هذا الجمال ونوعه وتشترك كلها في خضوعها للقو انين الكونية في النسب و العلاقات ونظام النمو وعلينا ان ننظر نظره تأمل وفحص الى خلايا النحل والاصداف والطيور والنباتات و الزهار و الحيو انات و الصخور فسوف نجد ان هذه العناصر هي التي توحى الينا وتعلمنا قانون الخلق الفني" • (1، صل صو (1)

فلو نظرنا الى عنصر الحيوان نجد الانسان اعتمد عليه في غذائه و ايضا استئناس منها حيوانات مثل الكلب وهو من أول الحيوانات التي استئناسها الانسان ودربها للصبد وبعد ذلك تعلم الانسان استئناس الحيوانات التي كان يصيدها لطعامه مثل الابقار وغيرها من الحيوانات ونرى ايضا انا كل نوع من انواع الحيوان يمثل جزءًا مهما من النظام الطبيعي الفريد فالحيو انات تساعد على بناء الحياه حيث تمثل غذاء للبشر وللنباتات وهى في الوقت نفسه تحفظ التوازن الطبيعي لأنها تتغذى على الحيوانات الاخرى و النباتات وهذا التوازن مهم في الطبيعة ويسمى دوره الحياه . وقد لا يستطيع البشر الحياه دون مساعده الحيو انات فالدور الذى تؤديه في حفظ التوازن الطبيعي يعد خدمه مقدره للبشرية فضدا عن ان الحيوانات تمد الانسان بعدد من الاغذية المختلفة مثل اللحوم والالبان والبيض و المنتجات المفيدة للكساء منل الصوف و الفر اء و الحرير • "وبرغم ان فنون مصر قديمها وحديثها ظل يرتبط بالكائنات الحيه تشكيليا الا انها اختلفت وتعددت في تتاول الصياغة وفى فلسفه الرؤية فلقد رسم الانسان البدائي نفسه وهو يقهر الوحوش على جدران الكهوف وذللك حتى يدفع عنه الخوف ويجعلها تعويذه سحريه يتغلب بها على الحيوان او 


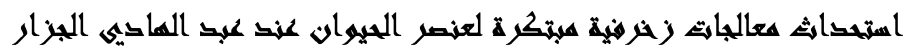

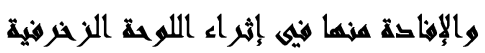

الوحوش المفترسة ولكن حينما تناولها الفنان في العصور المصرية القديمة (الفرعونية) كانت تأخذ مغزى دينيا فلقد عبر من خلالها عن بعض الآلهة من وجه نظره وعن الموضوعات المأخوذة من الو اقع و الفنان القبطي كان يتتاول موضوعات دينيه مصوره والفنان الاسلامي تتاول عناصر الحيوان بشكل زخرفي يجمل به منتجاته اما فنان العصر الحديث و المعاصر فلقد تتاوله بشكل من التحرر فالتعدد والتغير في صياغه الكائن الحى او الحيوان وظهوره بأكثر من رؤيه في الاعمال الفنية هي من سمات الفنان الحقبقي

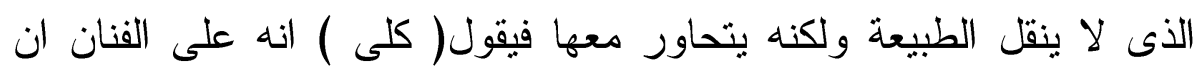
يجهد نفسه ليسمع اصوات الطبيعة" . (ץ، صبّ) فتصميم اللوحة الزخرفية هو احد انواع التصميمات الزخرفية التي ترتبط بموضوع محدد ومكان محدد ومساحه بعينها وتلعب الخامات وتقنيه التنفيذ دورا هاما بها وعلى المصمم ان يصيغ عناصره التشكيلية بطريقه زخرفيه وان يكيف اشكاله وتز اكيبه وفقا لما يتطلب هذه العو امل و القيمة التي يسعى الى تحقيقها وتصميم اللوحة الزخرفية انما يقوم على اثكال ومفردات زخرفيه هندسيه او مجرده وان يقوم على مفردات عضويه من الطبيعة ومن ضمن هذه المفردات الطبيعية العضوية التي يمكن ان ترد في اللوحة الزخرفية هو عنصر الحيوان ولذلك يتجه هذا البحث الى محاوله التعرف على الفنون القديمة و الحديثة التي تتاولت عنصر الحيوان في اعمالهم الفنية بهدف الاستفادة من هذه الصياغات في استلهام صياغات حديثه للحيوان في اللوحة الزخرفية المعاصرة . 


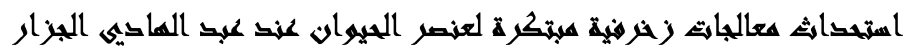

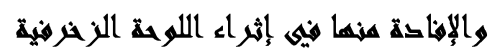

مما دفع العديد من الفنانين المصريين منذ بدايات الحركة الفنية

التشكيلية في مصر حتى اليوم الى الاستلهام من هذه الفنون في اعمالهر . ويعد الفن الشعبي احد الفنون التي اشتهرت بتتاول الاساطير و التقاليد المصرية الشعبية وعبرت عنها بصياغات فطريه مذهله ولهذا يتجه الدارس الى اعمال احد الفنانين المصريين المحدثين الذين اهنموا بدراسة الفنون و الاساطير الشعبية المصرية ومعايشتها والاستلهام دنها وهو الفنان عبد

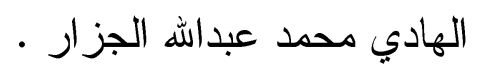

ان الجزار لم يغمض عينه عن العادات المتأصلة في مجتمعنا ولم ينبذها كما فعل غيره باعتبار ها مظهر ا من مظاهر التخلف وانما جعلها نقطه البدء لانطلاقه لا تحدها حدود ومن الرموز ذات السمه الشعبية و المستمدة من اصاله تراث الاساطير في الفن المصري القديم هي عنصر (القطه) ويستخدمها الجزار في كثير من اعماله لكونه يحاكى مغذى ذو دلاله تعبيريه حول ( الخير و الفال الحسن) ومن الرموز الثعبية الاخرى التي استخدمها الاسد و الحصان و الكف والعين و غير ها من الرموز المختلفة . ومن خلال تعدد الصياغات الجمالية والتشكيلية لعنصر الحيوان في أعمال الفنان عبد الهادي الجزار يمكن للباحث استحداث معالجات زخرفية مبتكرة لعنصر الحيوان والإفادة منها في أثز اء اللوحة الزخرفية.

\section{مشكانd البحث:}

من خلال دراسة الباحث للدراسات السابقة و التي تتاولت الصياغات التشكيلية لعنصر الحيوان لاحظ انها دائمًا تتناول عنصر الحيوان كمفرده تشكيليه في فنون الحضار ات القديمة البدائية و المصرية و القبطية و الاسلامية 


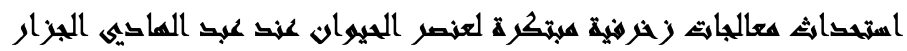

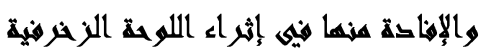

وكذلك كان الفن الشعبي بأساطيره وحكاياته الشعبية من الفنون التي كان لعنصر الحيو ان فيها دوره التشكيلي و التعبيزي المتميز. ولم تتطرق هذه الدراسات بالقدر الكافي لعنصر الحيوان في التصوير المصري الحديث فقد برز من الفنانين التشكلين فريق اتجه الى الفن الشعبي يستلهمون من منبعه الثرى وموضو عاتهح الشعبية و التعبيرية بما تزخرفه من مفردات تشكيليه عضويه ومنها عنصر الحيوان ومن خلال اطلاع الباحث على اعمال هؤلاء المبدعين من الفنانين المصريين المحدثين الذى استلهموا قيم ومقومات الفن الشعبي بعناصره النشكيلية يتجه الباحث الى عالم الفنان المتميز عبد الهادي الجزار الذى وجد الباحث في اعماله تعدد الصياغات التشكيلية لعنصر الحيوان الذى يمكن ان يستلهم فيه الباحث صباغات مستحدثه في تصميم اللوحة الزخرفية المعاصرة.

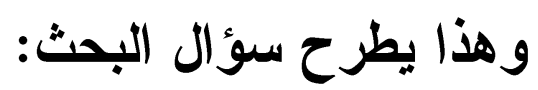

هل يمكن استحداث معالجات زخرفية مبتكرة لعنصر الحيوان عند

$$
\text { اهداف الهادي الجزار لإثز اء اللوحة الزخرفية؟ }
$$

1- الكشف عن التعدد في الصياغات التشكيلية لعنصر الحيوان عند عبد

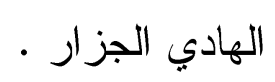

r- التعرف على العوامل المؤثزة في تعدد الصياغات التشكيلية لعنصر

$$
\text { الحيوان. }
$$

r- الافادة من تعدد الصياغات التشكيلية لعنصر الحيوان عند عبد الهادي الجزار كمدخل لتصميم اللوحات الزخرفية . 


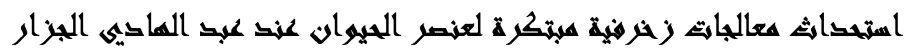

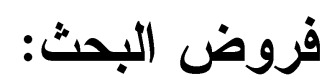

1-يفترض الباحث انه يمكن الافادة من تتوع المعالجات الزخرفية

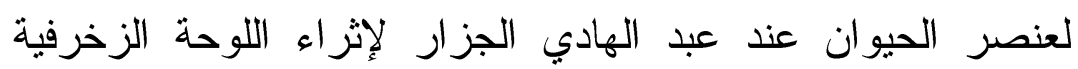

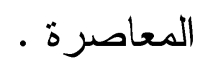

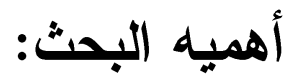

1- تدخل هذه الدراسة في تناول التراث من رموز وعناصر الفن الثعبي

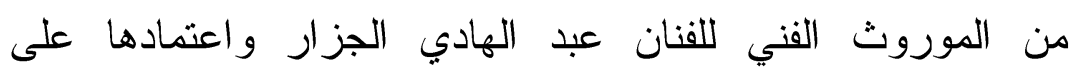

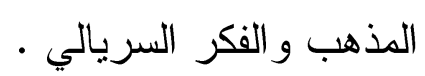

ץ- القاء الضوء على اسليب فنبه وحلول نثكيليه استخدمها الفنان لإيجاد حلول ومعالجات متتوعه لعنصر الحيوان والاستفادة منها في مجال

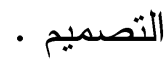

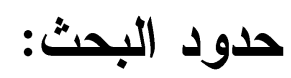

يقتصر البحث على دراسة عنصر الحيوان فقط عند عبد الهادي الجزار دون المفردات التثكيلية الاخرى .

تتحدد تجربه البحث في اجراء تطبيقات ذاتيه للباحث وذللك باستحداث الآنرث

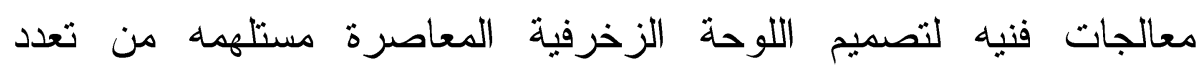
الصياغات التشكيلية لعنصر الحيوان عند الفنان عبد الهادي الجزار.

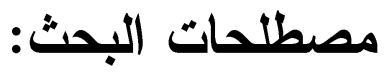
1-معالجات زخرفية: 


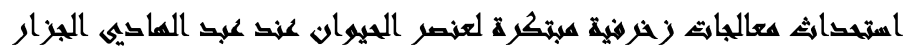

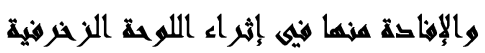

$$
\text { (عالج) الثيْ معالجة، و علاجًا زاوله ومارسه. (س، ص. • ع) }
$$

ويعرفها الباحث بأنها الممارسات والحلول الزخرفية المختلفة التي يمكن أن يستتجها الباحث من خلال نطويع عنصر الحيوان زخرفيًا وجماليًا في بناء اللوحة الزخرفية.

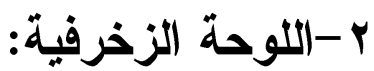

"هي بنية كلية منظمة لها عضوية العلاقات الزمانية و المكانية وتحقق المضامين الايديولوجية من خلال ديناميكية الصياغات التشكيلية للمفردات المختارة على أسس بنائية متتاسبة، ومنفذة بالتقنيات المتو افقة مع بنيتها الكلية بهدف تحقيق الدلالات التعبيرية والتي تعكس ما بداخلها من قيم جمالية خالصة". (ع، ص • (1)

و ايضًا تعرف بانها "هي احد انواع التصميمات الزخرفية التي تربط بموضوع محدد ومكان محدد ومساحه بعينها وتلعب الخامات وتقنيه التتفيذ

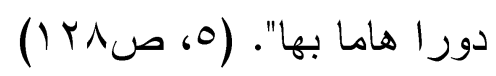
وعلى المصمم ان يصيغ عناصره التشكيلية بطريقه زخرفيه معاصره، "و ان يكيف اشكاله وتز اكيبه وفقا لما تتطلب هذه العو امل و القيمة التي يسعى

$$
\begin{aligned}
& \text { الى تحقيقها". (ד، ص(1) } \\
& \text { ب-التصميم الزخرفي: }
\end{aligned}
$$

"هو ترجمة لموضوع معين بفكرة هادفة لها علاقة بوسيلة التنفيذ وتحمل في جوانبها قيما فنيه ويتوقف نجاح التصميم على توزيع الخطوط الرئيسية وتوزيع الوحدات والعناصر الزخرفية المتنوعة المكونة للشكل العام وتنسيقها واتز انها وتزابط وتنسيق هذه العناصر ببعضها البعض في وحدة 


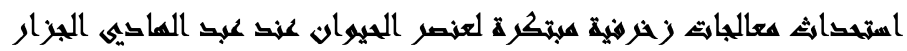

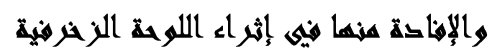

متكاملة تحقق الغرض المطلوب و حسن اختبار الألوان وتتسيقها و انسجامها".

$$
\begin{aligned}
& \text { (10) } \\
& \text { ع -تعريف الحيوان: }
\end{aligned}
$$

"هو عنصر من الكائنات الحيه التي تتميز بالخصائص التالية (الحركة - التغذية - التنفس- النمو - الاخراج- الاحساس- الانفعال التكاثز) و هذه الخصائص او المقاييس هي التي تميزها عن الكائنات الغير

$$
\text { حنه". (V، صب) }
$$

يتبع البحث المنهج الوصفي التحليلي في عرض الاطار النظري لموضوع الدراسة كما يتبع المنهج شبه التجريبي في تطبيقات البحث من خلال تجربة ذاتية للباحث ويتحقق ذلك من خلال اطارين:

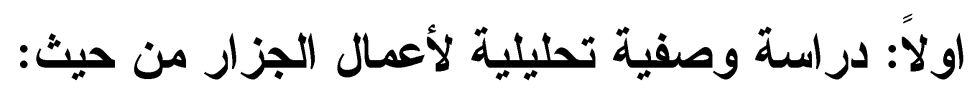
1- المؤثرات التي اثرت في فن الجزار.

ץ-تحليل بعض الصياغات التشكيلية لعنصر الحيوان عند الفنان عبد الهادي الجزار.

ثانيًا: استحداث معالجات زخرفية لعنصر الحيوان عند عبد الهادي الجزار في عمل لوحات زخرفية مبتكرة. اولاً: دراسة وصفية تحليلية لأعمال الجزار من حيث: ا - المؤثرات التي اثرت في فن الجزار: 


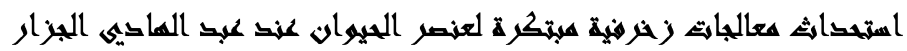

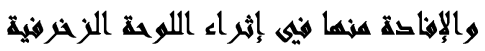

ولد عبد الهادي الجزار في حي القباري بالإسكندرية يوم (ع ال مارس عام 0ب9 ()، وكان ترنيبه الخامس بين اخواته الذين بلغ عددهم ثمانية، وقضى الجزار طفولته وشبابه في حي السيدة زينب بالقرب من تلال زينهم وهى من اقدم احياء القاهرة الشعبية و اكثرها فقر ا ولاحظ الاحياء الشعبية بما يوجد فيها من تقاليد مترسبة في جنبات الاحياء الشعبية، شاهد العادات الموروثة بين ابنائها (المواليد والافراح وحفلات الزار و الأحجبة و التمائم و الايمان بالسحر)، فكان النبع الاصيل لأعماله الفنية المبكرة، وفى بيئة دينية نشأة الجزار حيث كان والده فضيله الاستاذ الشيخ محمد عبد الله الجزار و الذى درس بالأزهر وعمل استاذاً بكلية الشريعة. "وفي جمعيه الرسم بمدرسه الحلمية الثانوية، تعرف الجزار على الاستاذ حسين يوسف أمين، هذا المفكر الذى كان يعمل مدرسا للرسم حينذاك و الذى شخل منصب(مفتش عام) التربية الفنية، ثم مدير ا للتعليم بالسويس بعد ذلك، ورغم ان هذا المفكر لم يقم بالتدريس للجزار سوى عامين، الا انهما كانا كافيين لا قامه علاقه دائمه بينهما، و عندما كون حسين يوسف امين جماعه الفن المعاصر عام (؟؟9 1) كان الجزار من اهم اعضائها، ومن اكثر افر ادها نشاطا وتميزا (^، صس-ع)، "واستمد الجزار إلهاماته من الجالين و المشعوذين وانماط البشر الخضر من كثره الوشم، والاذرع الغارقة في الاساور، و الكردان الذهب الذى تتدلى منه السلاسل و الشر اشيب، و انقاض المقاعد المهشمة، وذوى الجلاليب السوداء دن حاملي النعوش، و اكو ام العظام في القبور ورسم القطط والبوم، ودمبات وتعابين ومفاتيح واحجبه وسلاسل، 


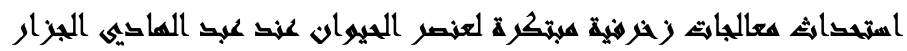

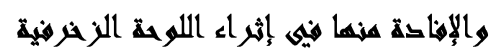

كل ذللك جعله يتعايش بين العقائد و التعاويذ واهل الذكر، و الاساطير و ابطال

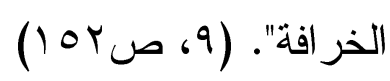

\section{تأثير المكان علي لوحات الجزار:}

"علاقه الفنان بالمكان علاقة تبادلية محققة ويكاد المكان يكتسب شخصية ذات وجود ملموس تطبع بسماتها وجدان الفنان، كما تطبع طقوس الحياة ذاتها ومن ثم يأتي النتاج الفني من صنف البيئة التي يتعامل معها بحيث قد يصل الأمر لدى بعض الفنانين من فرط سطوة المكان إلى ان يضحي الفنان أداة المكان من اجل أن يتجسم وتصبح اللوحة (مكان في علاقته بذاته)". $(9 \operatorname{ar}) \cdot)$

"ان الجزار لم يغمض عينه عن العادات المتأصلة في مجتمعا، ولم ينبذها كما فعل غيره باعتبار ها مظهر من مظاهر التخلف، انما جعلها نقطه البدء

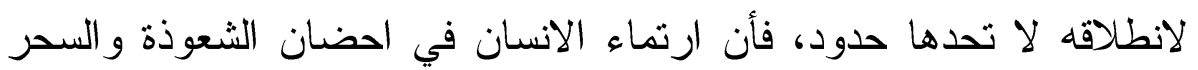
و التعاويذ والاحجبة، ليس الا وسيله سلبيه للاحتماء من المجهول او الدفاع عن النفس ضد قدر غيبي غير متوقع" (1)، صسا))، ان النظرة التي يلقيها الجزار على الاساطير الشعبية لم تكن نظره الايمان بها و انما نظره النقا الإز ع لها، فكان يجمع بين التعبيرية و السريالية لكى ينتج تصورًا اجتماعيًا لهذه الظو اهر شأنه ان يعبر بطريقته الخاصة عن موقفه الخاص إزاء الحياه

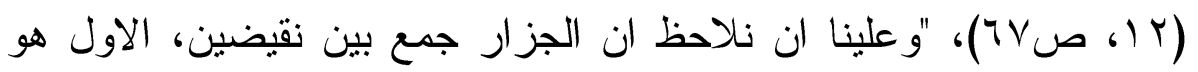
الاحساس بالحياة متداخله ومتأثره بالفكر الاسطوري و الميتافيزيقي نتيجة لحياته في الاحياء الثعبية، و الثاني هو الوعى الفكري و العلمي نتيجة لانتمائه للطبقة الوسطى و الى المثقفين من ابناء هذه الطبقة، مع اهنماماته ودر استه 


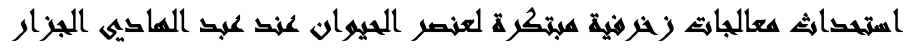

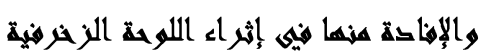

العلمية، فقد اتجه في دراسته الثانوية الى الجوانب العلمبة، وحصل على شهاده التوجيهية(اي الثانوية العامة) متخصصا في (القسم العلمي)" (س (ه

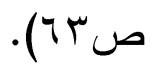

ا-تحليل بعض الصياغاث التشكيلية لعنصر الحيوان عند الفنان عبد

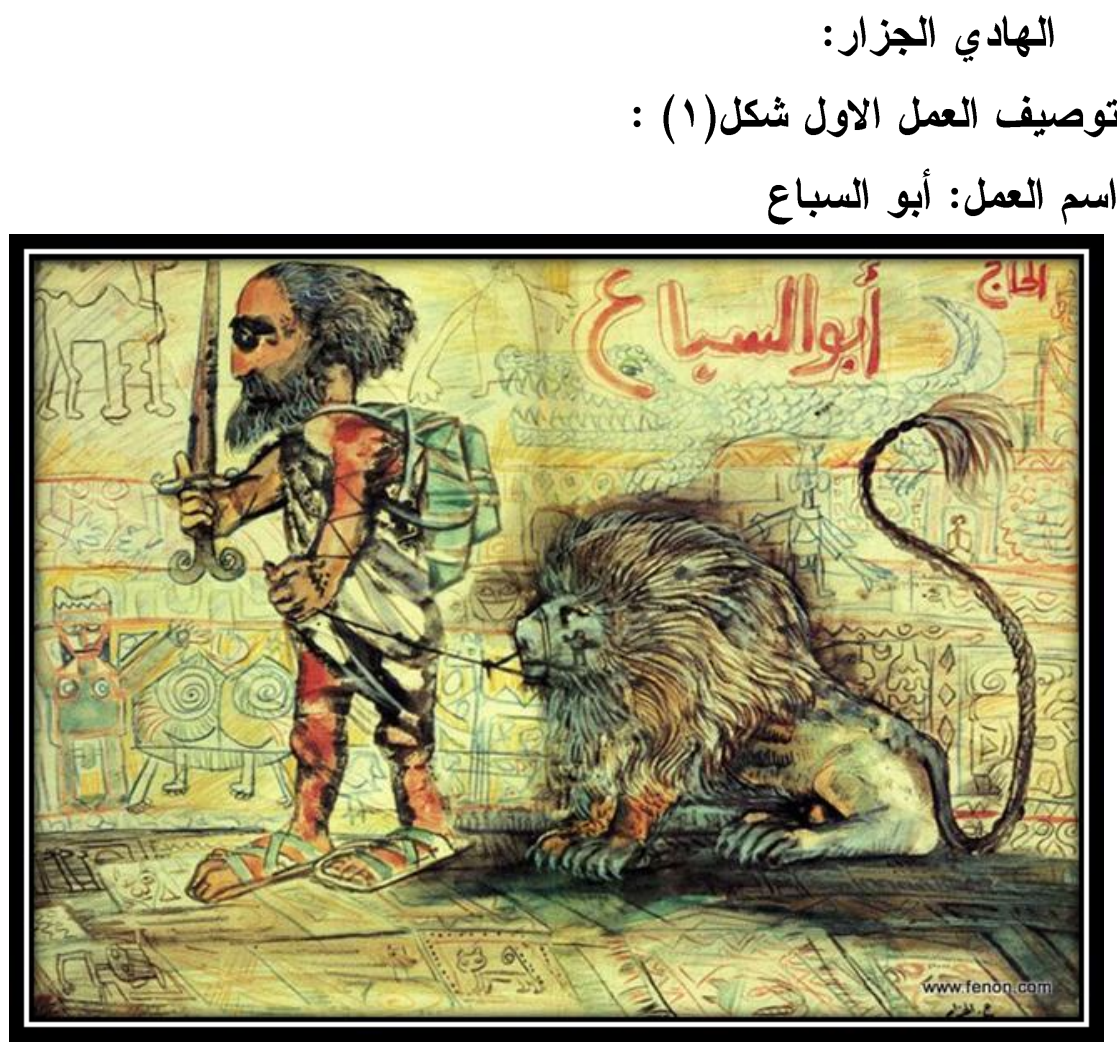

شكل) (1) 


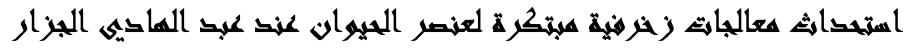

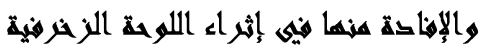

\section{http://www.fineart.gov.eg}

عبد الهادي الجزار، أبو السباع، ألوان مائية وأقلام ملونه، حبر شيني على

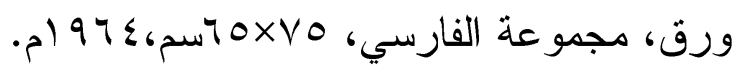

ونرى في هذا العمل مشهد للسبرك الشعبي فنجد مدرب في السيرك

يسحب وراءه أسده بحبل كأنه يسحب حيوان أليف، ونجده يتحرك هو و الاسد ربما يكون هذا مشهد لرحيل السيرك حيث نرى الددرب يحمل متاعه خلف

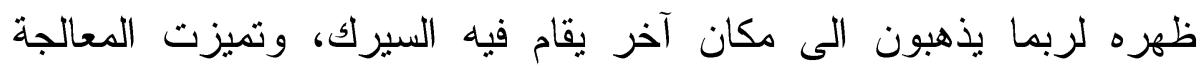

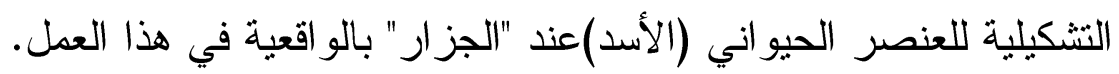

توصيف العمل الثاني شكل(r) :

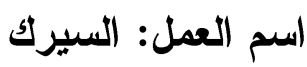




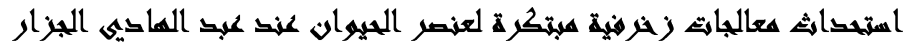

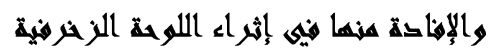

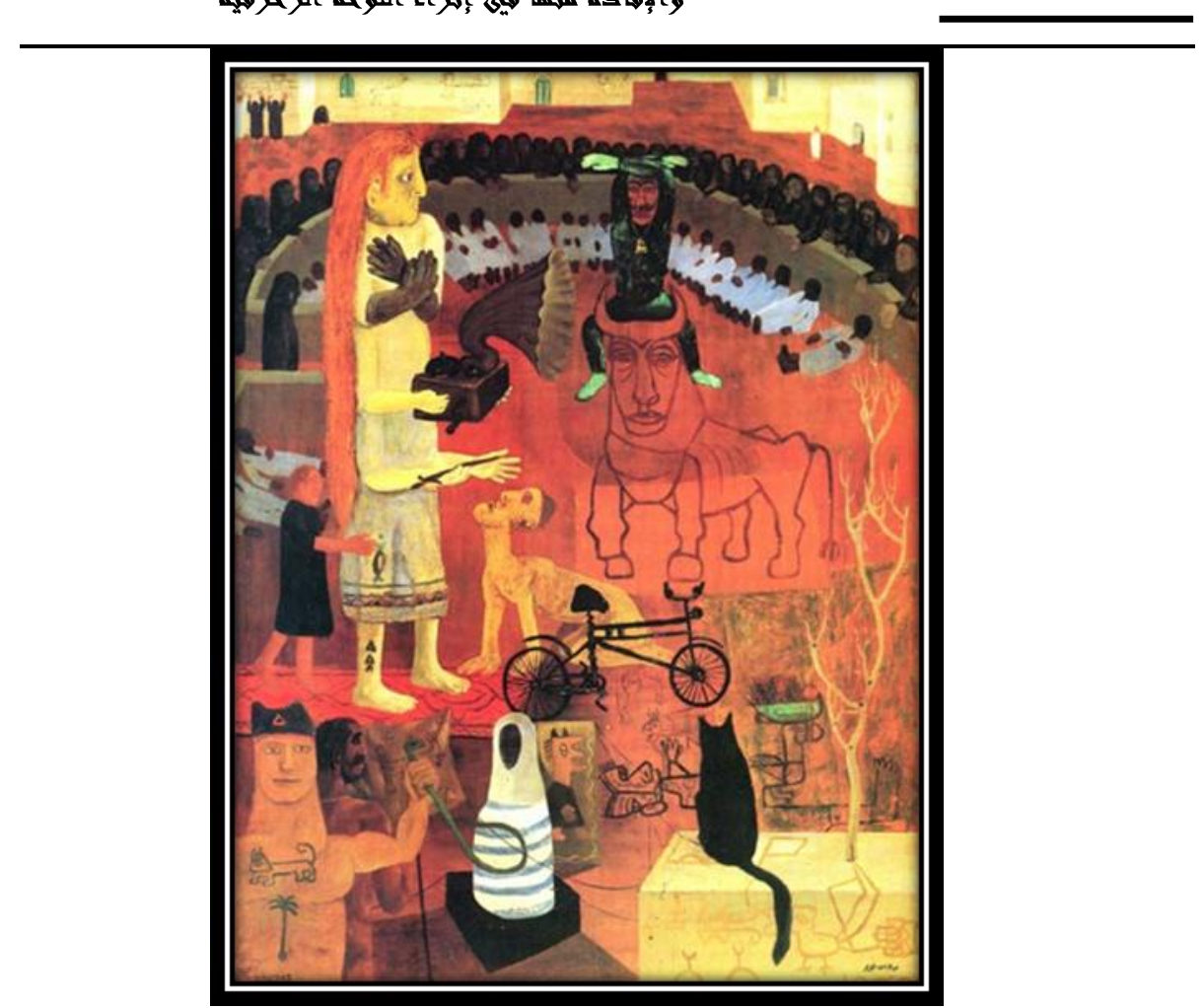

الثكل(r)

http://www.fineart.gov.eg

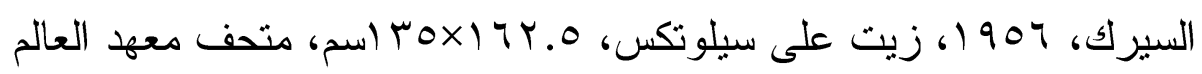
العربي بباريس.

في هذا العمل مزج الجزار العناصر كلها لكى يعبر عن مفهوم السيرك لباريت عنده وهو (الحياة الشعبية) بكل سلبياتها وتناقضاتها، ونلاحظ استخدام الفنان

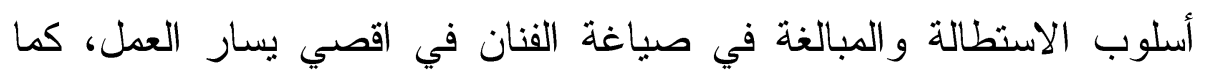

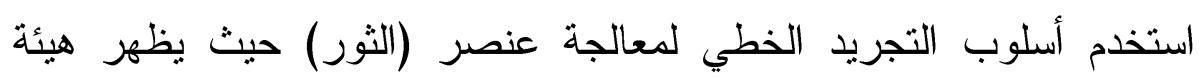
العنصر وقوته واستعاض عن ملامح الوجه بملامح وجه إنسان. 


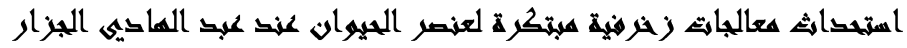

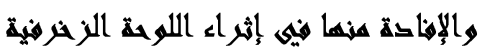

توصيف العمل الثاني شكل(ب) :

اسم العمل: عاشث من الجن

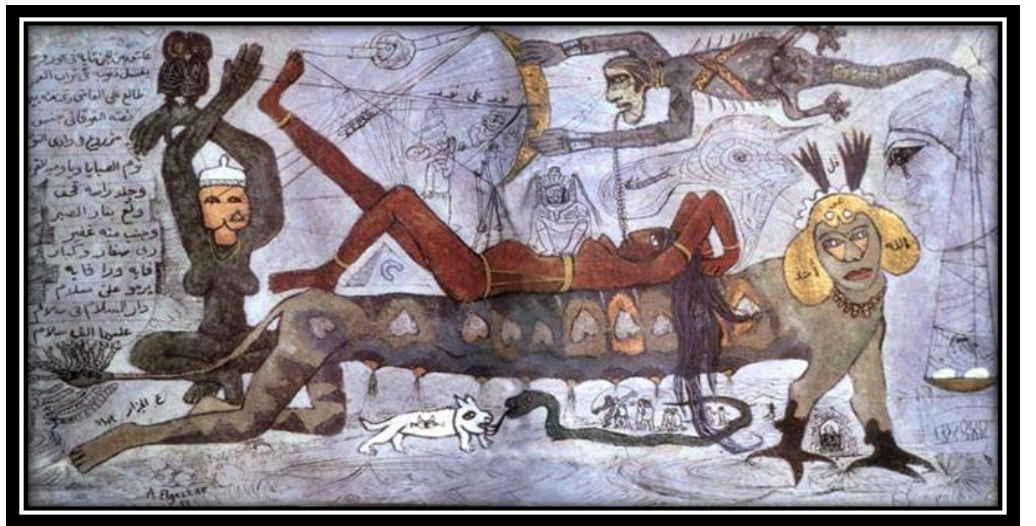

شكل) (r)

http://www.fineart.gov.eg

عاشق من الجن، س0190، حبر شيني وجواش على ورق، متحف الفن الحديث بالإسكندرية.

لقد استخدم الفنان في هذا العمل أسلوب التحوير والمبالغة في صياغة الكائن الخرافي حيث صاغ الجسم بأسلوب المبالغة في هيئة أسد له رأس إنسان والأقدام الأمامية لطائر والأقدام الخلفية لإنسان، وله ذيل حيوان وله لهان بطن طويلة ينزل منها اللبن من تسع اماكن، كما صاغ عنصر البرص بأسلوب محور مهولة رأس انسان وأيدي إنسان، كما صاغ صياغتان للعنصر الآدمي احدهما لفتاه على ظهر الكائن الخر افي والأخرى لفتاه منشابكة الأيدي في يسار اللوحة تحمل فوق يديها بومة بأسلوب التحوير أيضًا فنجد ان الجو العام للعمل سريالي، فلقد عالج الفنان خلفية العمل معالجات خطية لمجموعة من العناصر المختلفة لتزبط العمل ببعضه. 


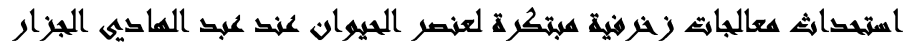

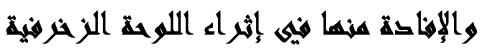

توصيف العمل الثاني شكل(ع) :

اسم العمل: قارئ البخت

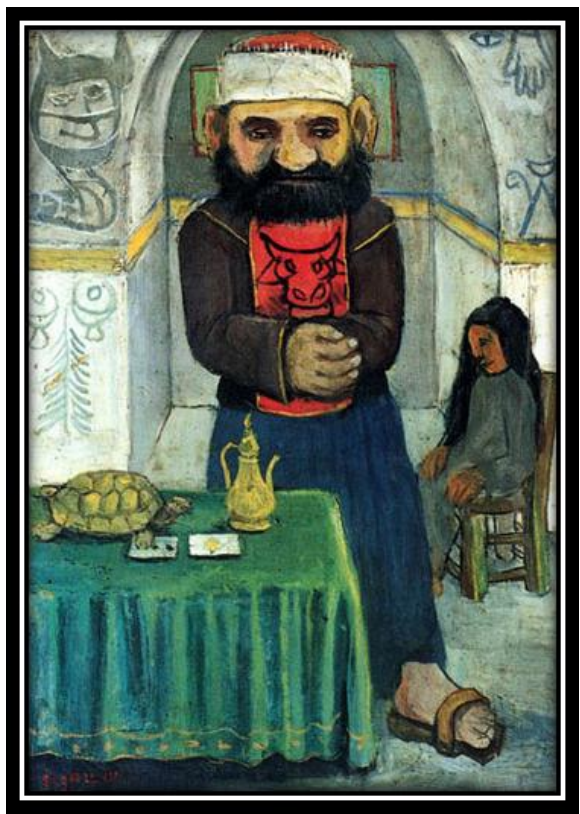

شكل (ع)

http://www.fineart.gov.eg

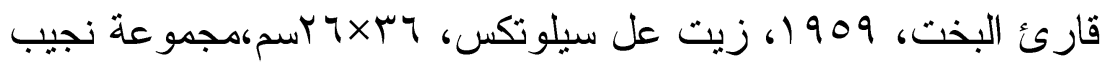
ساويرس.

ونري في هذا العمل قارئ البخت و اقفًا وهو يرتدي عمة الشيوخ ويطلق لحيته ويضع يديه كأنما يصلى متخذًا قبلته المشاهد، وهذا يدل على أنه يتخذ الدين ستارًا لأعماله التي يحرمها الدين وينهى الناس عن ارتكبها ويكفر من يقوم بها، ونرى رأس ثور مرسومة على صدر قارئ البخت على مساحة 


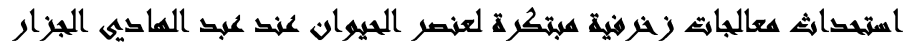

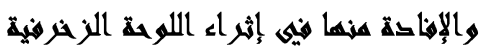

حمر اء تجذب العين لها كأنها تدل على تسخير الجن الاحمر له، فلقد صاغ الفنان رأس الثور على صدر العنصر الآدمي بأسلوب خطي. توصيف العمل الثاني شكل(0) : اسم العمل: عربة السيرك

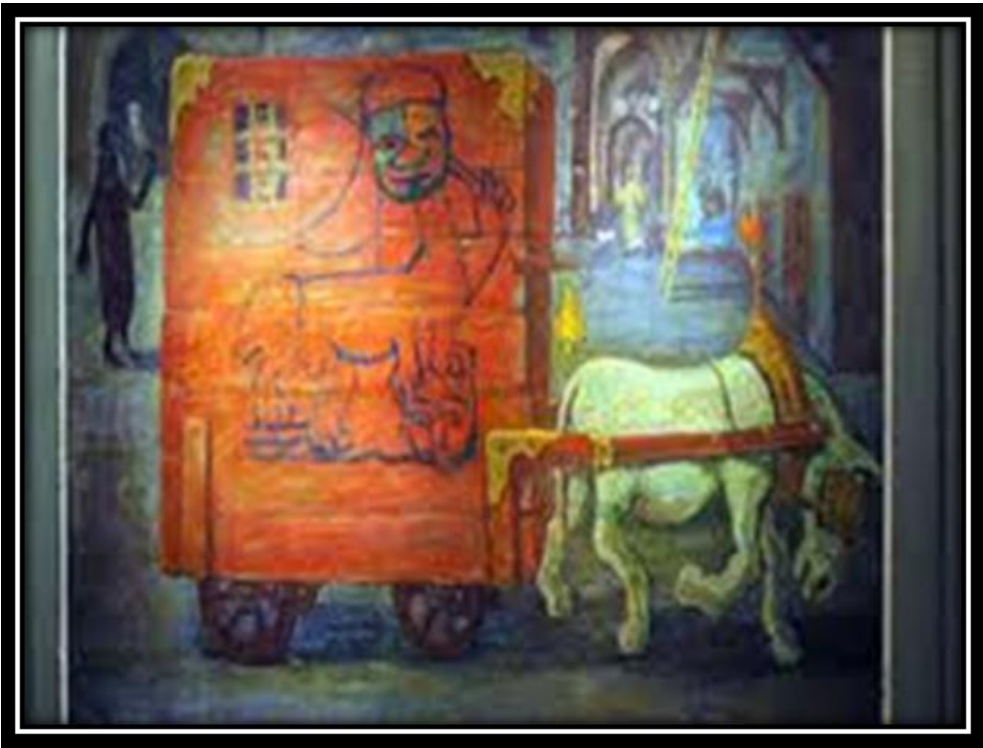

شكل) شart (0)

http://www.fineart.gov.eg

عبد الهادي الجزار، عربة السيرك، زيت على خشب، ابلكاش،

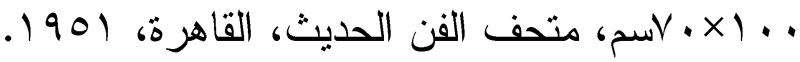

وفي هذا العمل نرى عربة حمراء من عربات السيرك الشعبي بطل

علينا من داخلها رجل من نافذة لها قطبان، ونرى على العربة رسم شعبي لأسد له راس آدمية يحمل في يده سيفًا و اليد الأخرى يدوس بها على رأس

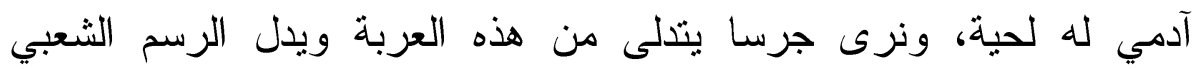




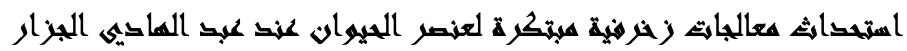

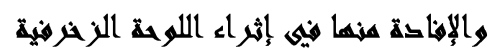

الموجود على العربة بانها عربة مروضي الوحوش، فلقد استعان الفنان في

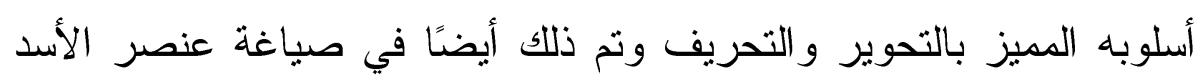
وهى مستوحاة من الفن الشعبي ونفذت بأسلوب خطي على مسطح عربة السيرك.

"هكذا تتميز اعمال (عبد الهادي الجزار) بالدر امية العنيفة و التعبير

عن الموضوعات بانفعال قوى و عاطفة جياشة و التكامل بين الشكل و المضمون بدرجه يتعذر تو افرها لدى فنان اخر في حركتنا الفنية المعاصرة، كما اضاف الى لوحاته ظلالا من شخصيته الفذة وثقافته المتنوعة، حتى ليشعر المتلقي بالآلفة نحوها رغم غرابتها، ورغم انها تدفع الى التوتز و القلق و اعادة النظر في معنى الحياة، فهو يخاطب الجماهير بأسلوبها ورموزها و الوانها، ويلمس قلوب مثققيها وعقولهم، ويستهوى الذواقة بالجاذبية

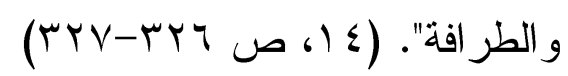

جدول يوضح الصياغات المتعددة لعنصر الحيوان عند عبد الهادي الجزار 


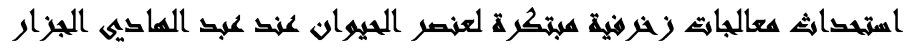

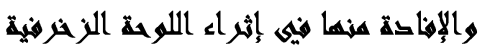

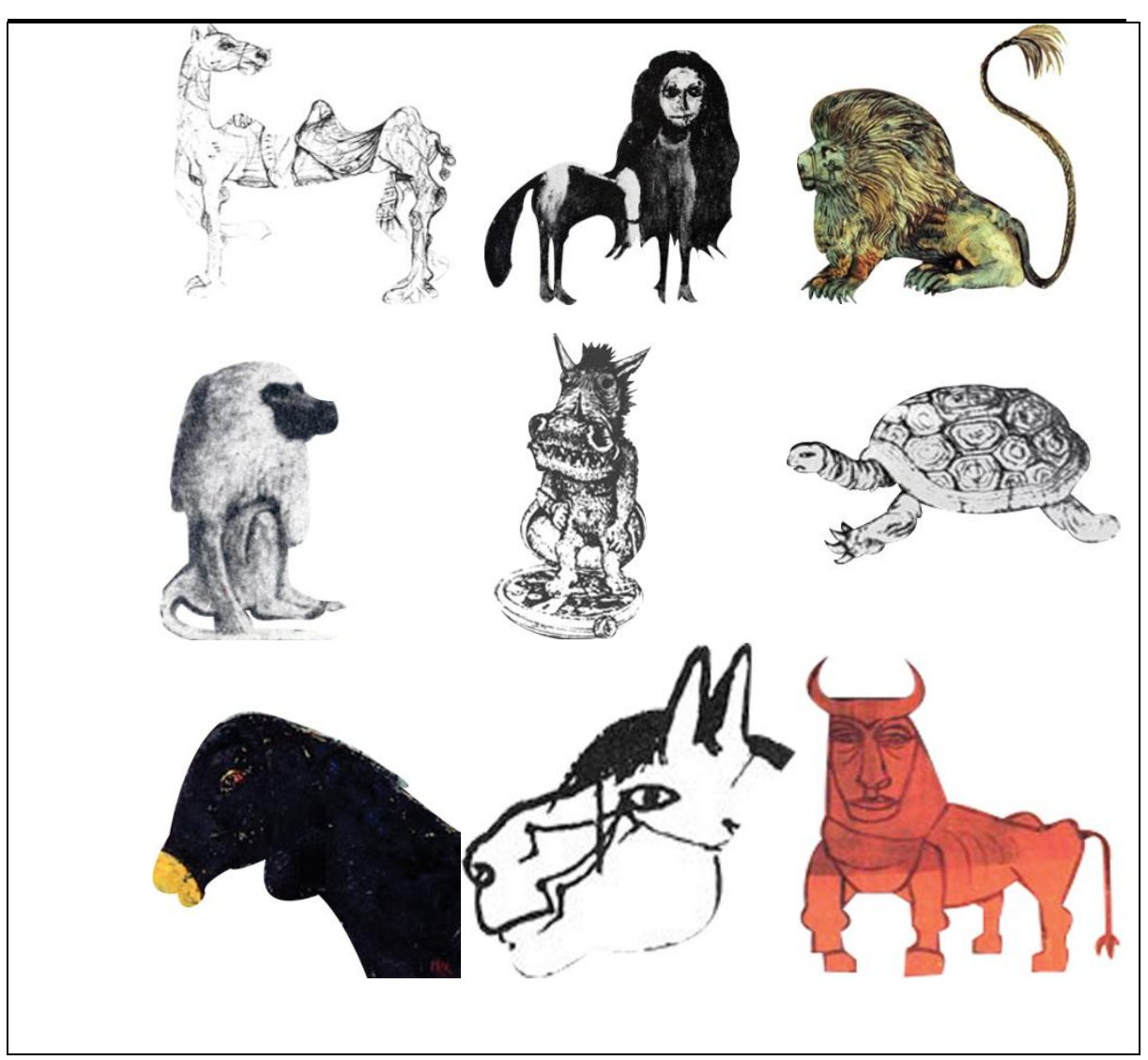

ثاتيًا : استحداث معالجات زخرفية لعنصر الحيوان عند عبد الهادي الجزار في عمل لوحات زخرفية مبتكرة طارح بذلك (خمسة) نماذج من تطبيقات الباحث كمثال وذلك للوقوف على إمكانية تحقيق الهدف من البحث وقد كان

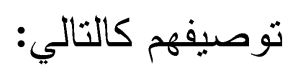

جدول يوضح تعدد الصياغات التصميمية لعنصر الحيوان قبل وبعد التحوير التي تمت من قبل الباحث 


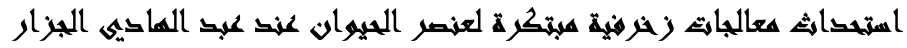

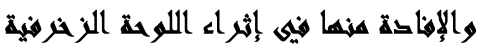

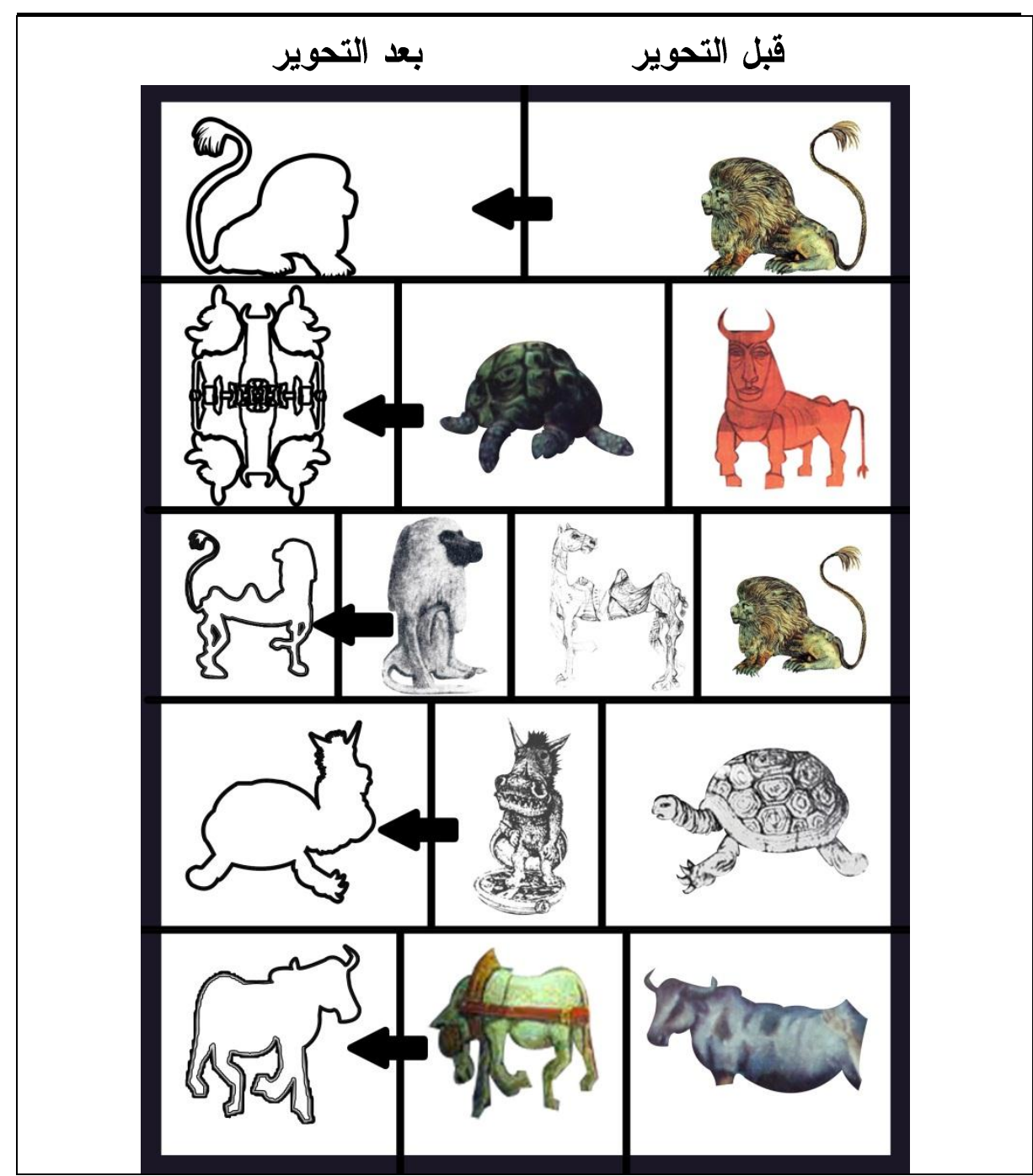

العمل الاول : 


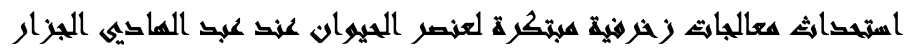

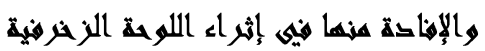

يقوم هذا التصميم على اساس التكرار و التز اكيب و التر اكم في العمل الفني مما ادي الي تحقيق نوع من الاتزان بتكرار المفردة الزخرفية بمختلف احجامها الكبيرة والصغيرة، فلقد كان لاختيار الالوان دور كبير في الاحساس بالتناغم و الايقاع داخل العمل الفني.

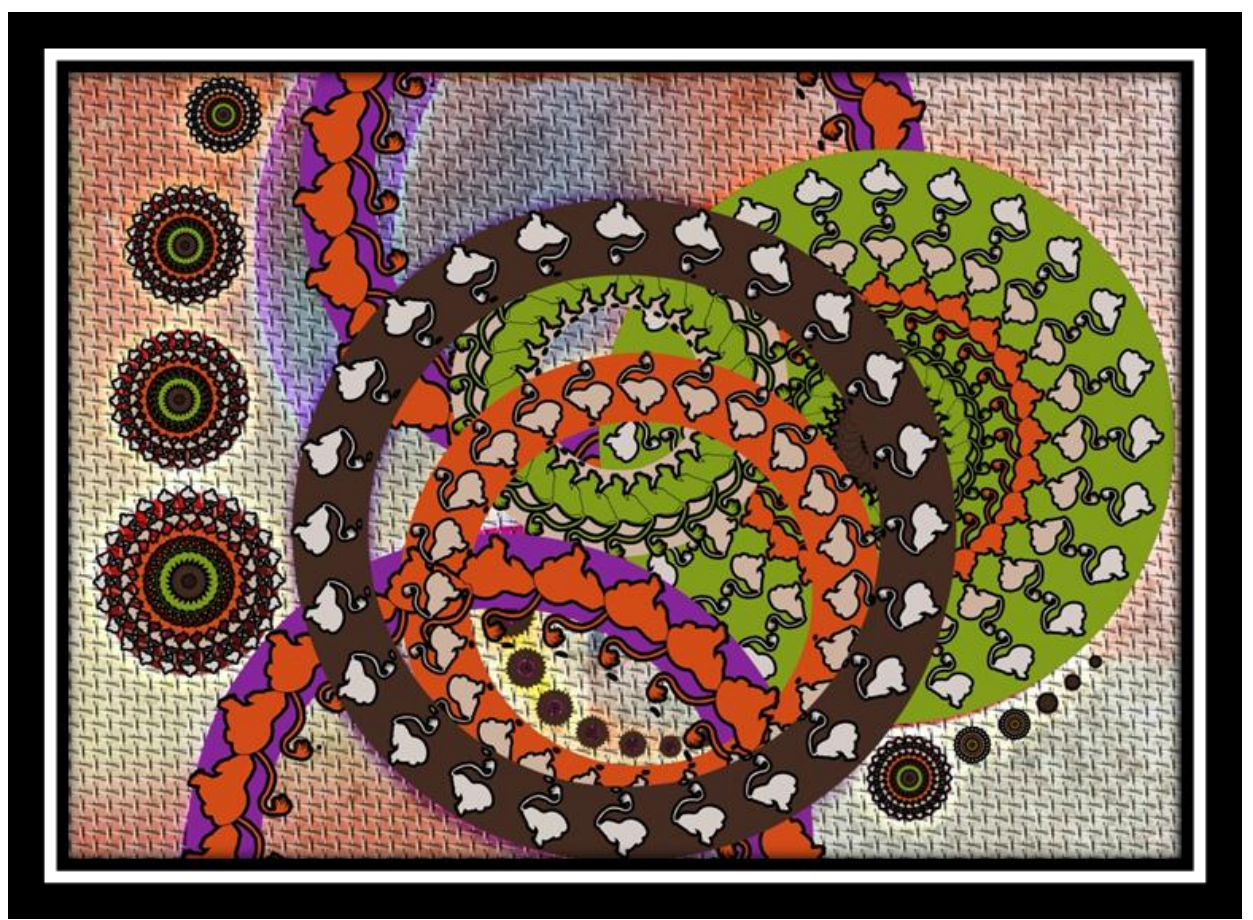

$$
\begin{aligned}
& \text { شكل(1) } \\
& \text { من عمل الباحث } \\
& \text { צ.V }
\end{aligned}
$$

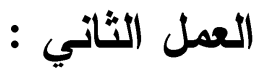




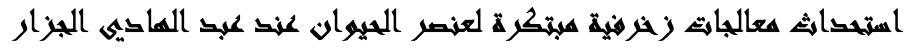

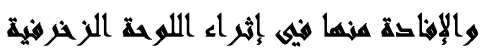

يعثمد هذا التصميم على الاثزان المتماثل في توزيع الوحدة الزخرفية داخل العمل الفني، كما ان اختيار الالوان ادي الي حدوث نوع من التتاغم والايقاع داخل العمل الفني ، واما خلفية العمل قد اعثمدت على اشكال الوحدة المتمثلة في التصميم الزخرفي على اساس العلاقات التكر ارية المتساوية.

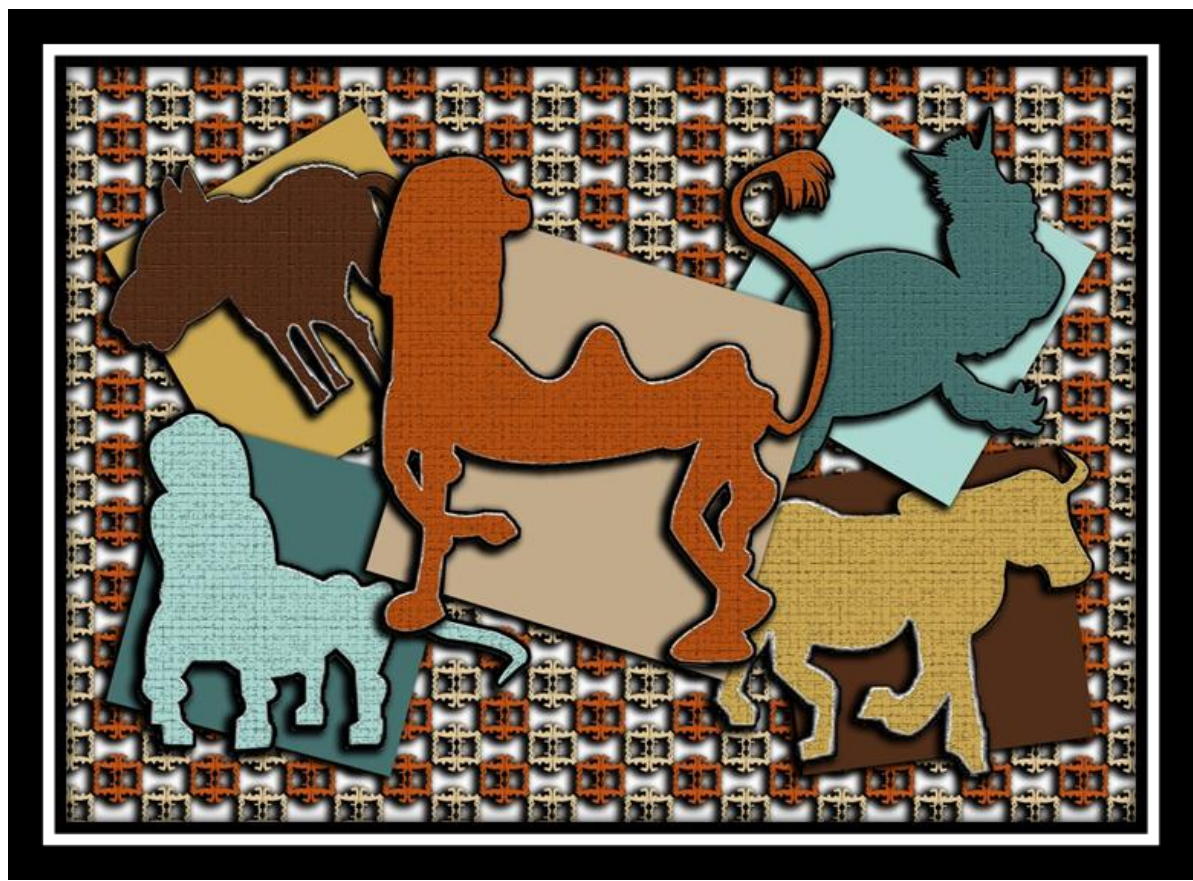

$$
\begin{aligned}
& \text { شكل(r) } \\
& \text { من عمل الباحث } \\
& \text { צ.V }
\end{aligned}
$$

العمل الثالث : 


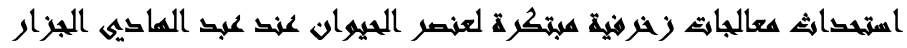

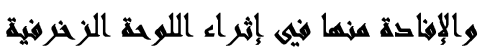

يتضمن هذا التصميم اكثز من وحده زخرفية تنشكل في مجموعات بنظام تكر اري متتاظر ومحوري ، كما ان حركة المفردات داخل العمل الفني ادث الي جذب نظر المشاهد وايضًا ادت الي حدوث نوع من الايقاع داخل العمل الفني، و ايضنًا اختيار الوان العمل ادي الي حدوث تتاغم داخل التصميم.

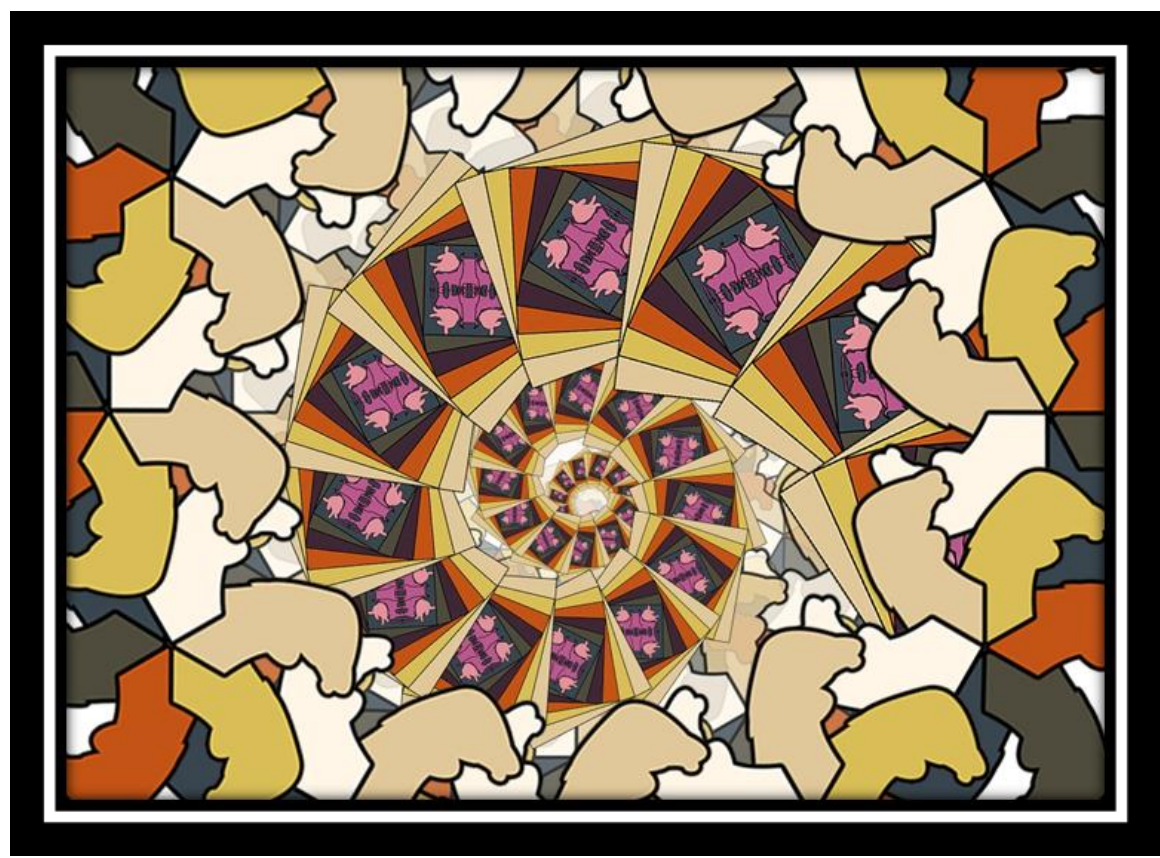

شكل) (r)

من عمل الباحث

Q

العمل الرابع : 


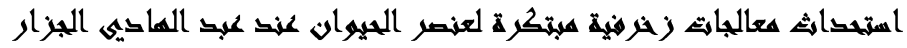

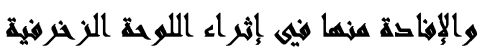

يعتمد هذا العمل على أساس تكرار المفردة الزخرفية مدا أدي الي تحقيق نوع من الاتزان داخل العمل الفني، كما ان حركه المفردة داخل العمل الفني أدت الي حدوث نوع من الايقاع داخل العمل الفني وايضًا أدث الي جذب انتباه المشاهد للعمل.

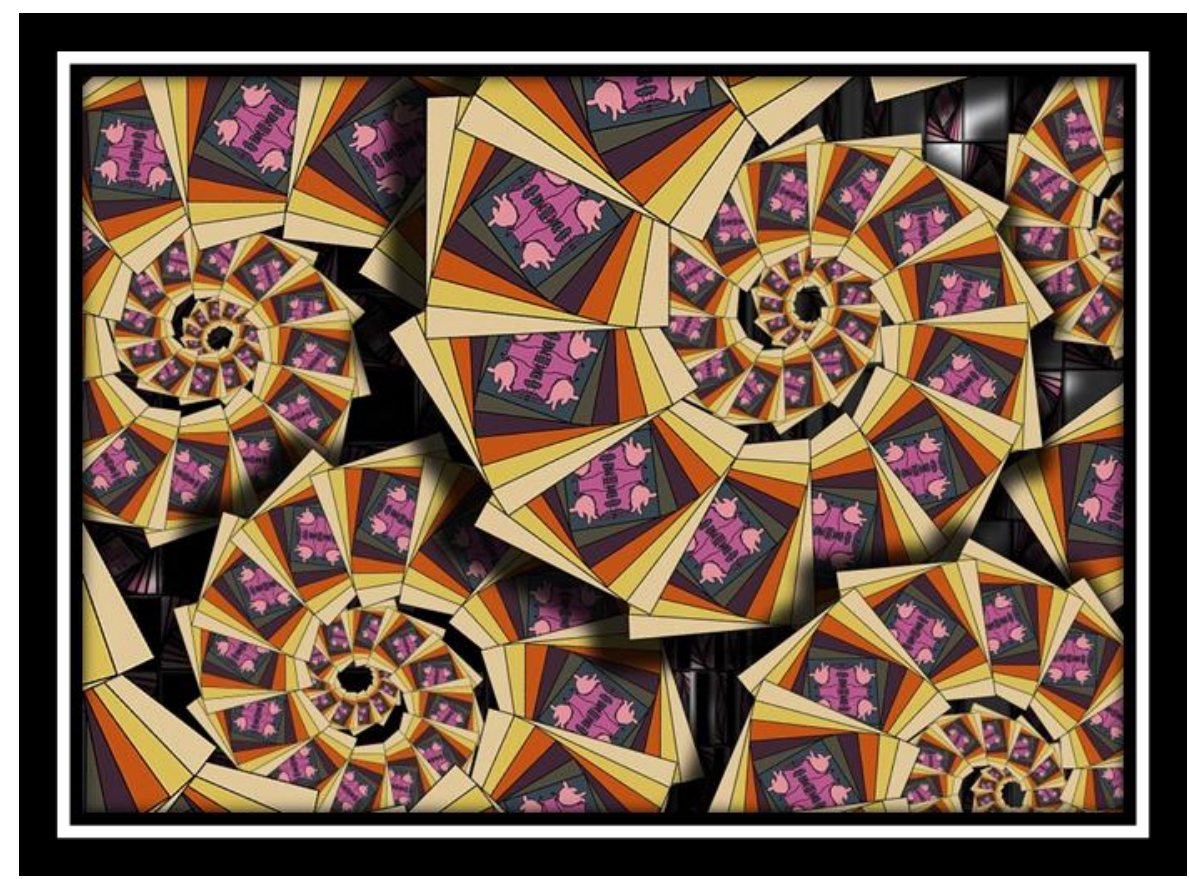

$$
\begin{aligned}
& \text { شكل(§) } \\
& \text { من عمل الباحث } \\
& \text { צ.V. }
\end{aligned}
$$

العمل الخامس : (المس 


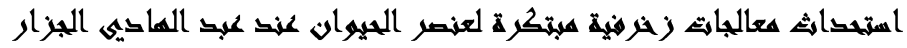

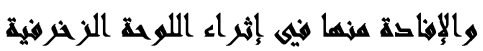

يقوم هذا التصميم على الاتزان المتماثل في توزيع الوحدة الزخرفية داخل العمل، كما ان اختيار الالوان ادى الي حدوث نوع من التناغم والايقاع داخل

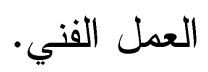

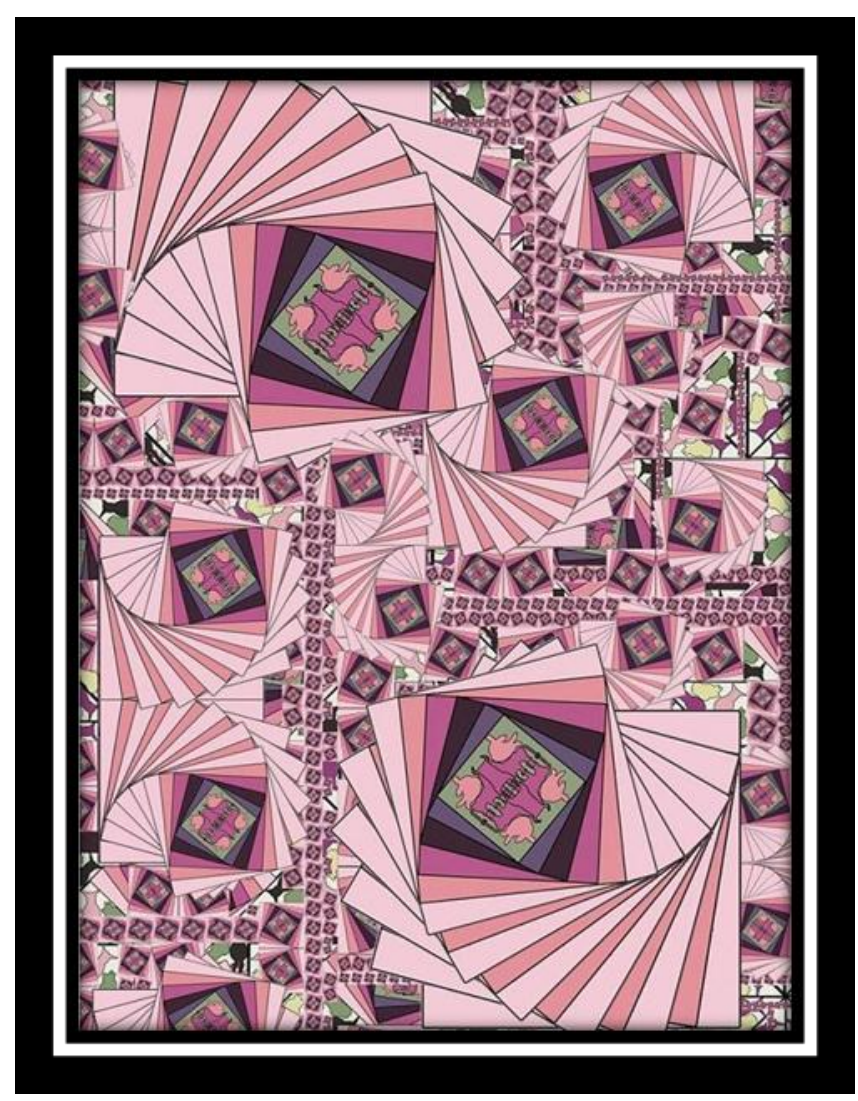

$$
\text { من شكل(0) عمل الباحث }
$$




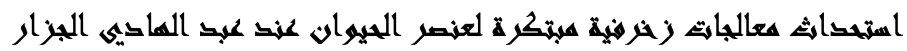

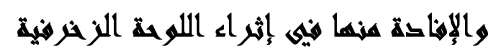

النتائجج

1- اظهرت الدراسة ان المعتقدات و المعارف الشعبية كان لها أثر كبير

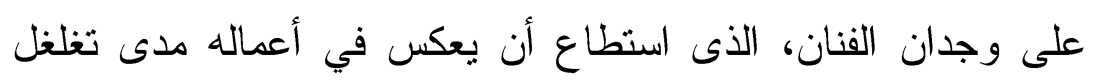
هذه المعتقدات و المعارف الشعبية في وجدان الناس.

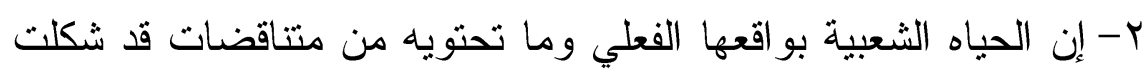

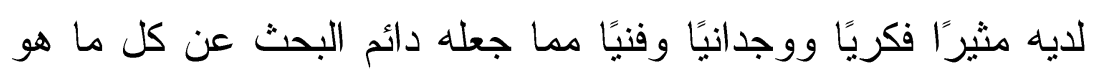
أصيل في المجتمع المصري. r- أظهرت الدراسة نجاح الفنان في توظيف لغة الرمز، لتعبير عن مفاهيم ومعتقدات و عادات راسبة لاى الناس.

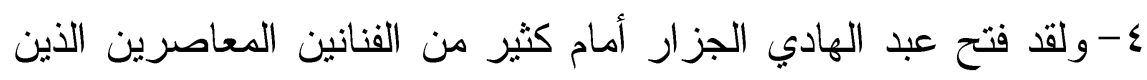

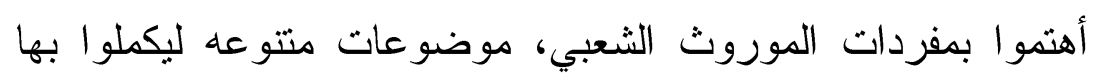
عناصر اعمالهم الفنية. التوصياث :

1-ضرورة عمل دراسات مقارنة لتوظيف الرموز ذات الدلالات

الشعبية و المستقاه من البيئة الشعبية في اعمال مصورين آخرين.

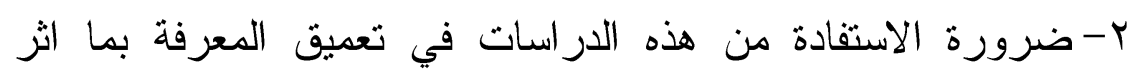

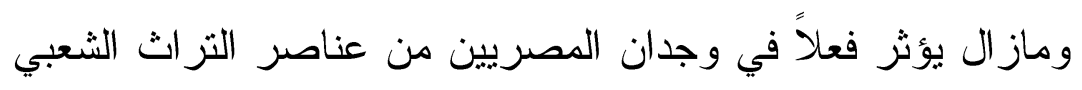
المصري.

ץ-ضرورة الاهتمام بدراسة تاريخ الفن وتحليل الأعمال الفنبة المتعلقة

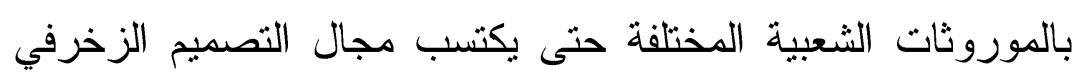
بعدًا جديدًا عند ابتكار وتتفيذ لوحه زخرفية من هذه الاعمال. 


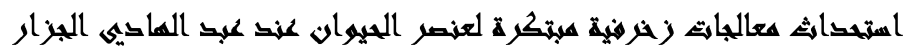

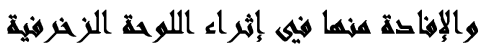

\section{مراجع البحث:}

أولاً : المراجع العربية:

1- ابو صلاح الالفي : (الموجز في تاريخ الفن العام)، دار نهضه دصر لمباعة و النشر، القاهرة.

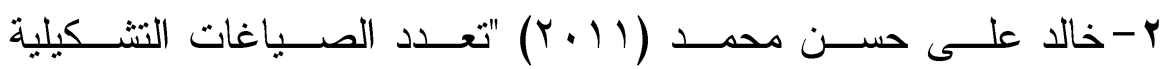

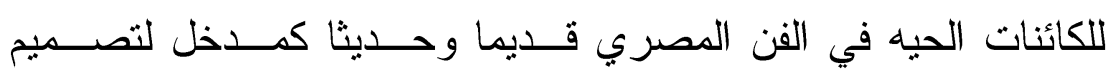

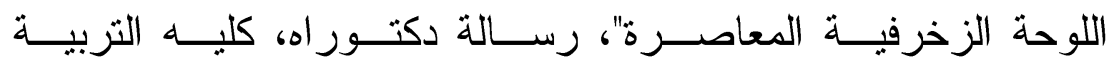
النو عية، جامعة عين شمس.

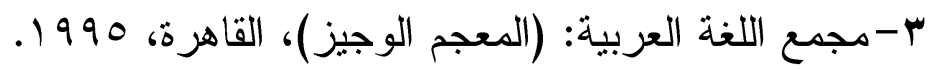

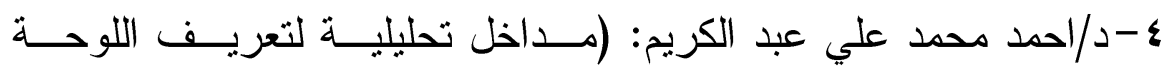

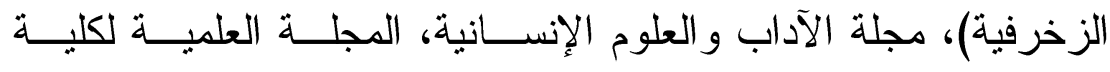

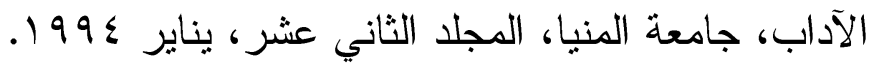

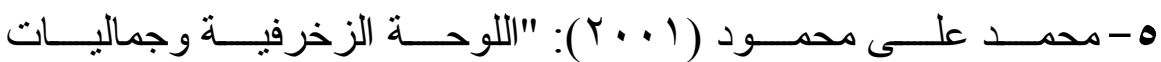

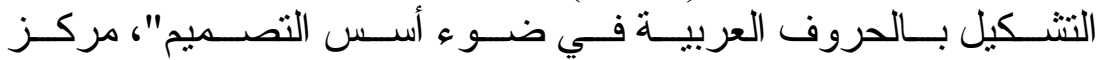

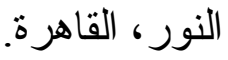

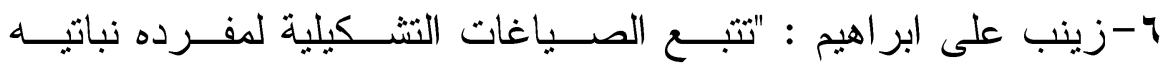

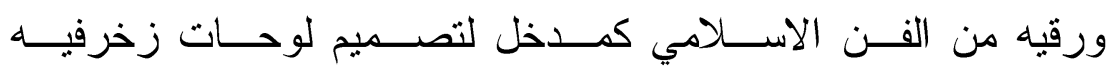

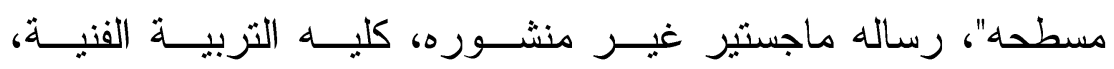

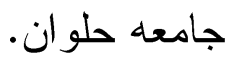

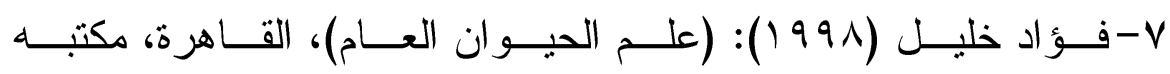

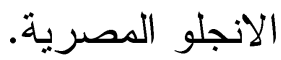




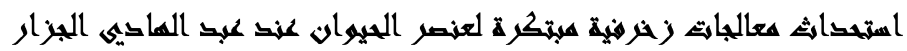

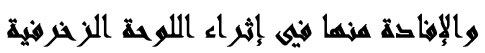

1-صبحى الثـارونى (ب79 1): عبد الهادي الجـزار (فنــان الاســاطير

و عالم الفضاء)، القاهرة: الدار القومية للطباعة و النشر.

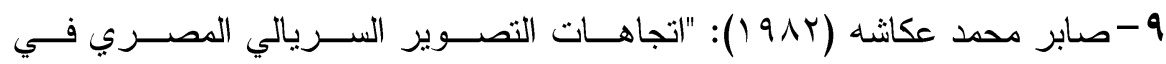

القرن العشرين"، رساله ماجستير، كليه التربية الفنية، جامعة حلوانه انوان.

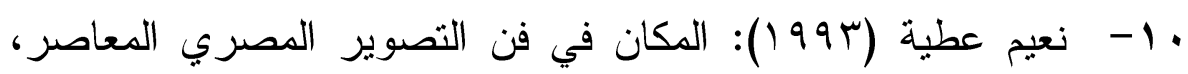
القاهرة: الهيئة المصرية العامة للكتاب بالتعاون مع الجمعية لنقاد الفن التشكيلي.

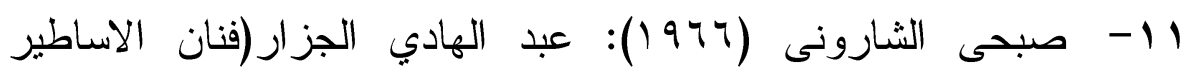
و عالم الفضاء)-الدار القومية للطباعة و النشر .

r ا- يوسف فرنسيس (•991): عبد الهادي الجزار فنان مصري، القاهرة: دار المستقبل العربي.

سا- آلان، وكرستين روسيون (99 (1)): عبد الهادي الجزار فنان مصري، القاهرة: دار المستقبل العربي.

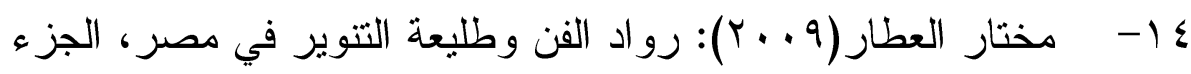
الاول،عدد9، من سلسله دراسات في نقد الفنون الجميلة، القاهرة: الهيئة العامة للكتاب. ثانيًا: مواقع الاتثرنت :

15-http://forums.fonon.net/archive/index.php/t-9954.html 16-http://www.fineart.gov.eg 